Article

\title{
Enhancement of Ecological Field Experimental Research by Means of UAV Multispectral Sensing
}

\author{
Ricardo Díaz-Delgado ${ }^{1, * \mathbb{C}}$, Gábor Ónodi ${ }^{2}$, György Kröel-Dulay ${ }^{2}$ and Miklós Kertész ${ }^{2}$ \\ 1 Remote Sensing and GIS Laboratory (LAST-EBD). Estación Biologica de Doñana. CSIC. Avda. Américo \\ Vespucio 26, 41092 Sevilla, Spain \\ 2 MTA Centre for Ecological Research, Institute of Ecology and Botany, Alkotmány 2-4, \\ H-2163 Vácrátót, Hungary; onodi.gabor@okologia.mta.hu (G.O.); \\ kroel-dulay.gyorgy@okologia.mta.hu (G.K.-D.); kertesz.miklos@okologia.mta.hu (M.K.) \\ * Correspondence: rdiaz@ebd.csic.es; Tel.: +34-954-232-340
}

Received: 23 November 2018; Accepted: 28 December 2018; Published: 7 January 2019

check for updates

\begin{abstract}
Although many climate research experiments are providing valuable data, long-term measurements are not always affordable. In the last decades, several facilities have secured long-term experiments, but few studies have incorporated spatial and scale effects. Most of them have been implemented in experimental agricultural fields but none for ecological studies. Scale effects can be assessed using remote sensing images from space or airborne platforms. Unmanned aerial vehicles (UAVs) are contributing to an increased spatial resolution, as well as becoming the intermediate scale between ground measurements and satellite/airborne image data. In this paper we assess the applicability of UAV-borne multispectral images to provide complementary experimental data collected at point scale (field sampling) in a long-term rain manipulation experiment located at the Kiskun Long-Term Socio-Ecological Research (LTSER) site named ExDRain to assess the effects on grassland vegetation. Two multispectral sensors were compared at different scales, the Parrot Sequoia camera on board a UAV and the portable Cropscan spectroradiometer. The NDVI values were used to assess the effect of plastic roofs and a proportional reduction effect was found for Sequoia-derived NDVI values. Acceptable and significant positive relationships were found between both sensors at different scales, being stronger at Cropscan measurement scale. Differences found at plot scale might be due to heterogeneous responses to treatments. Spatial variability analysis pointed out a more homogeneous response for plots submitted to severe and moderate drought. More investigation is needed to address the possible effect of species abundance on NDVI at plot scale contributing to a more consistent representation of ground measurements. The feasibility of carrying out systematic UAV flights coincident or close to ground campaigns will certainly reveal the consistency of the observed spatial patterns in the long run.
\end{abstract}

Keywords: unmanned aerial vehicles (UAVs); field experiments; LTSER; drought; multiscale approach; NDVI; Sequoia

\section{Introduction}

Climate change effects on ecosystems are being investigated at different spatial and temporal scales. Both observational and experimental approaches are being applied to identify trends, shifts and changes for different ecological indicators. Among the many initiatives, the Long-Term Ecological Research (LTER) networks are informing about the factors driving changes in biodiversity, the self-organizing capacity of ecosystems, the effects of rare events and disturbances, the impacts of stressors on ecosystem function and the interactions between short- and long-term trends [1]. These LTER networks rely on site-based monitoring and research by providing data and detecting 
trends identifying drivers and pressures on ecosystems and biota. The LTER networks' major contribution is the enlargement of temporal and spatial scales to test global research hypotheses. In this case, as in the NEON [2] and GCOS [3] networks, observational approach is the dominant method.

Experimental designs have been widely implemented to test research hypothesis in relation to climate change. Typically, field experiments are designed to replicate conditions at which single and multi-factor effects occur. Factors are controlled and effects are measured during a predetermined period or in few cases for the long run such as ANAEE [4] or Drought-Net [5]. At plot scale, climate manipulation experiments are a particularly effective way to study the ecological consequences of climate change [6]. However, they are normally conceived to collect measurements at a certain spatial scale, usually related to plot size or sampling method [4]. Only few experiments are planned which follow a multiscale approach. Historical examples are the Oregon Transect Ecosystem Research Project [7] or the HiWATER [8] which used remote sensing images together with ground-truth data. Nevertheless, the experimental ecologist is hard-pressed to find specific guidance for the design, execution and analysis of experiments to produce results that account for scale-dependent effects [9].

Remote sensing has traditionally been proposed as the essential tool to scale down the processes observed with the help of the images provided either by Earth observation satellites or airborne cameras/sensors and ground measurements. While covering the gradient from global to local scales, remote sensing has been providing critical information to map changes and trends [10]. In the last decades, remote sensing scientists are thoroughly investigating upscaling procedures to integrate multiscale information for any observation of ecological relevance [11,12]. Major advances have been reached in precision farming [13] mostly by using thermal, multi and hyperspectral airborne sensors. However, there is a lack of research in multiscale approaches using remote sensing for long-term ecological and climate change experiments [4]. There are many high and very high-resolution sensors on board of Earth observation satellites providing images with spatial resolution going from a few meters to tens of centimetres. Such availability enhances the multiscale approach but the high-resolution images are costly and have to be pre-ordered and acquired over the study area. High-, medium- and low-resolution scenes are periodically acquired by the orbiting satellites collecting a time series of images illustrating temporal changes and trends at the landscape scale. The fine resolution satellites or airborne campaigns may help in detailed habitat mapping, for instance while dramatically increasing costs. Yet, Unmanned Aerial Vehicles (UAVs) can be flown over the same area as frequently as required, only constrained by weather conditions or legislation, becoming a suitable tool to map either elements or processes. As a major trait, UAVs provide the opportunity to define spatial resolution as detailed as requested according to the mission objectives [14]. Remote sensing UAV is becoming very useful in cropland monitoring [15,16] and precision farming [17]. It is also being widely applied for environmental assessment [18] and similar studies on grasslands have addressed sensor comparison for leaf area index estimation with ground measurements and UAV acquisitions [19]. Few studies are focusing on upscaling essential variables from natural vegetation making use of UAV and multispectral sensors [14,20].

As an expected consequence of global warming, extreme events are becoming more frequent across ecosystems including extreme and sudden droughts causing vegetation die-offs and community shifts [21]. Extreme drought events can reduce primary production [22] and community functional diversity [23]. At plot scale, climate manipulation experiments are particularly effective way to study ecological consequences of climate change, especially long-term multi-site field experiments [6,24]. This is the case of the ExDRain experiment set out at Kiskun LTER station where rain manipulation is applied since 2014 for several plots after the application of extreme drought event for some of them [25]. Ecosystem recovery is assessed by periodically measuring plant cover and biomass using NDVI (Normalized Difference Vegetation Index, [26]) collected using a portable CropScan MSR87 multispectral radiometer (Cropscan, Inc., Rochester, MN, USA) as a non-destructive method [27]. Cropscan has 8 narrow (10 nm bandwidth) spectral bands centred at 460, 510, 560, 610, 660, 710, 760 and $810 \mathrm{~nm}$ (bands 660 and 810 are usually used for NDVI calculation). However, the plant community 
is composed by several grassland species and the response to treatments is very heterogeneous [6] due to different phenology and structure. Plots are larger than Cropscan footprint measurement and UAV complementary information might help in providing ancillary information enhancing the assessment on treatments effects.

In this work we assess the applicability of UAV-borne multispectral and RGB (Red-Green-Blue) cameras to enhance experimental data by providing complementary information. We check the correlation between data collected at point (field sampling) and plot (UAV sampling) scales and analyse new observed patterns in relation to the effects of the ExDRain experiment on the vegetation. We question whether NDVI-derived from UAV multispectral images acquired at lower scale are in coherence with Cropscan point measurements. On the other hand, we examine the information provided by UAV images and assess the effects of experimental treatments at plot scale, by which we hypothesize that effects at different scales may be different and can enhance the interpretation of the observed results.

\section{Study Site and Experimental Design}

\subsection{Kiskun LTER Site}

The Kiskun LTER site is located in the Kiskunság National Park $\left(46^{\circ} 52^{\prime} \mathrm{N}, 19^{\circ} 25^{\prime} \mathrm{E}\right)$ in a Pannonian sand forest-steppe vegetation mosaic [25] of high plant diversity and nature protection value [28]. It is included into the Kiskun LTSER (Long-Term Socio-Ecological Research) platform (Figure 1). The Kiskunság region is located in Central Hungary covering 14,000 $\mathrm{km}^{2}$. It is an extremely heterogeneous sandy area, consisting of arable fields, abandoned pastures, planted forests and extensive natural and semi-natural habitats from xeric grasslands to salt marshes. The soil is calcaric arenosol which enhances the semidesert character of the vegetation. Climate of the study area is temperate continental. The vegetation period starts in April and finishes in October. Based on regional 30 years average values (1961-1990), mean annual temperature is $10.4^{\circ} \mathrm{C}$, mean monthly temperature ranges from $-1.9^{\circ} \mathrm{C}$ in January to $21.1^{\circ} \mathrm{C}$ in July, while mean annual precipitation is $505 \mathrm{~mm}$ with a peak in June [29].

Kiskun LTER focuses on studying the effects of climate change (more extreme weather events and longer vegetation periods) and land use change (abandonment of arable fields, decrease of grazing and afforestation) on biodiversity as well as ecosystem functions and services in Kiskunság. According to climate change scenarios for Hungary, the frequency of extreme dry and wet years is expected to increase in the study region [30].

\subsection{ExDRain Experiment}

The experimental area represents the sand grassland of the continental semiarid forest-steppe biome of Central Europe. The purpose of the experiment is to investigate how extreme and moderate events interact by observing their single and combined effects on plant cover, abundance and biomass of the grassland species in the site. The experimental design takes the results of the multi-site EU FP5 VULCAN and the EU FP7 INCREASE projects [24,31,32] into consideration. In our study plots, we sampled open grassland patches of semi-arid perennial grassland dominated by C3 bunchgrasses. We study the ecosystem recovery following the extreme drought and how it is affected by experimentally reduced or increased precipitation.

One-off extreme drought treatment was created by excluding precipitation for five months in 2014. Starting in 2015 and repeating in each summer, four levels of long-term precipitation change are applied: (1) strong drought (2-months duration), (2) moderate drought (1-month), (3) control, and (4) water addition (four times per year, one per month between May and August, ca. $100 \mathrm{~mm}$ in total). The two (i.e., extreme and precipitation change) treatments are combined in a full factorial design $(2 \times 4=8$ treatment combinations), in six replications (Figure $1 \mathrm{c}, \mathrm{d}$ ) resulting in a total number 
of 48 plots of $3 \times 3 \mathrm{~m}$ size. Exclusion is reached by covering with plastic the corresponding plots and watering using irrigation diffusors (Figure 2).

Plant biomass was estimated by non-destructive field spectroscopy with a portable Cropscan MSR87 multispectral radiometer (Cropscan, Inc., Rochester, MN, USA) measuring at the same time incoming and reflected radiation. Cropscan measurements were taken always exactly at the same location placing the sensor above the plots at a height of $1.5 \mathrm{~m}$. With a field of view (FOV) of $28^{\circ}$, the Cropscan samples a circular area of $0.44 \mathrm{~m}^{2}$ (diameter: $0.75 \mathrm{~m}$ ) and the distance between measurement points of the neighbouring plots was $1 \mathrm{~m}$. The frame allowed us to repeat the sampling of each plot at the same position during the different measurement events. Plastic roofs were removed for every Cropscan measurement event. The last measurement for this study took place during the week of 23 to 27 July 2018.

From red $(660 \mathrm{~nm})$ and near infrared $(810 \mathrm{~nm})$ Cropscan reflectance values bands, we calculated NDVI . The NDVI provides an accurate proxy for plant aboveground green biomass estimation for pioneering plant communities $[27,33]$.
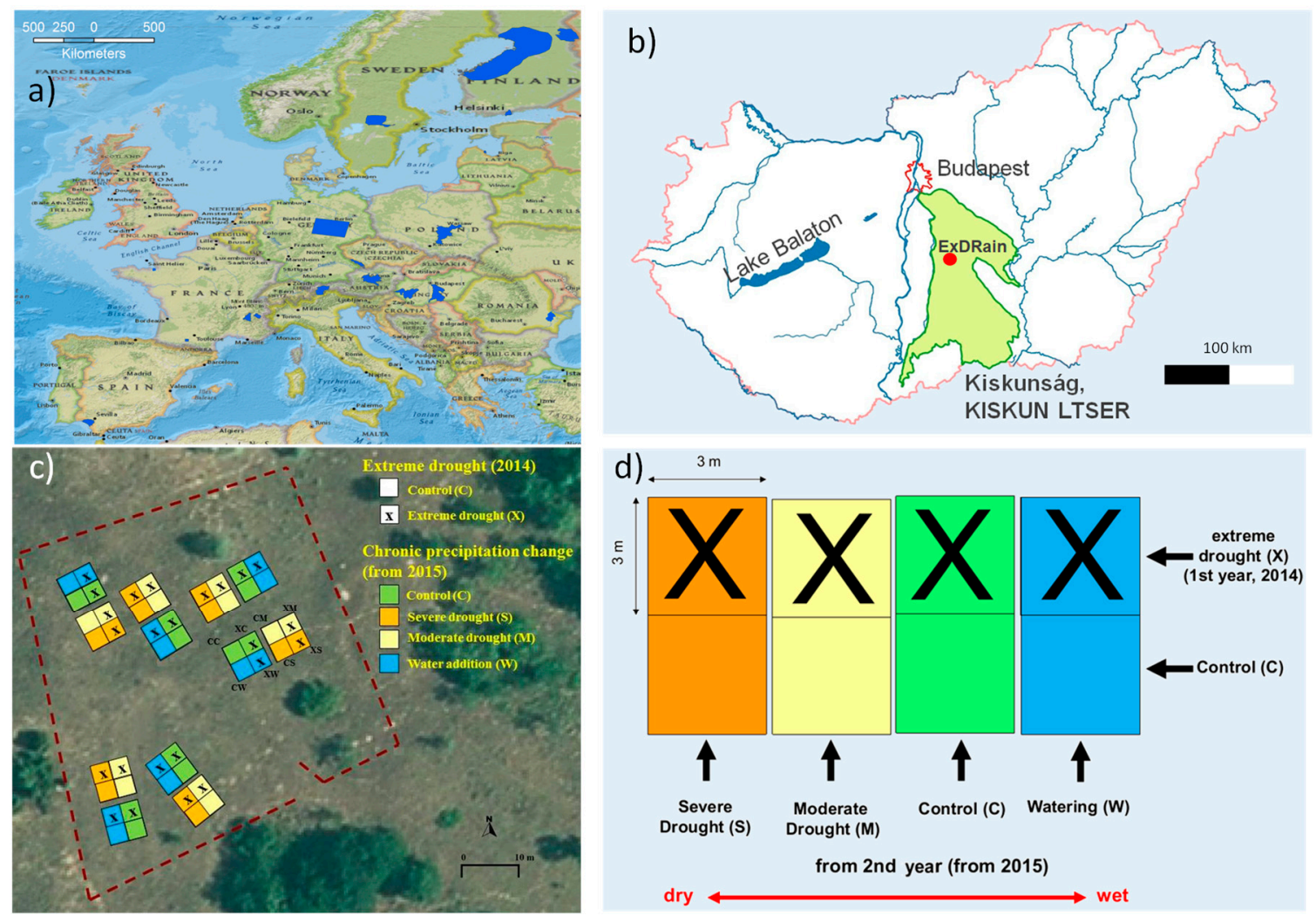

Figure 1. (a) Location of the 16 first Long-Term Socio-Ecological Research (LTSER) platforms declared in 2007 in Long-Term Ecological Research (LTER)-Europe [34] plus the three incorporated in 2010. Nowadays, the number has increased to 31 [35] and more have been created in other LTER regional networks [36]. (b) Location of Kiskun LTSER platform in Hungary (green area) and the ExDRain experiment site (red dot). (c) Details of experimental area with the different treatment plots. (d) Plot size and treatment legend by colours and crosses. 

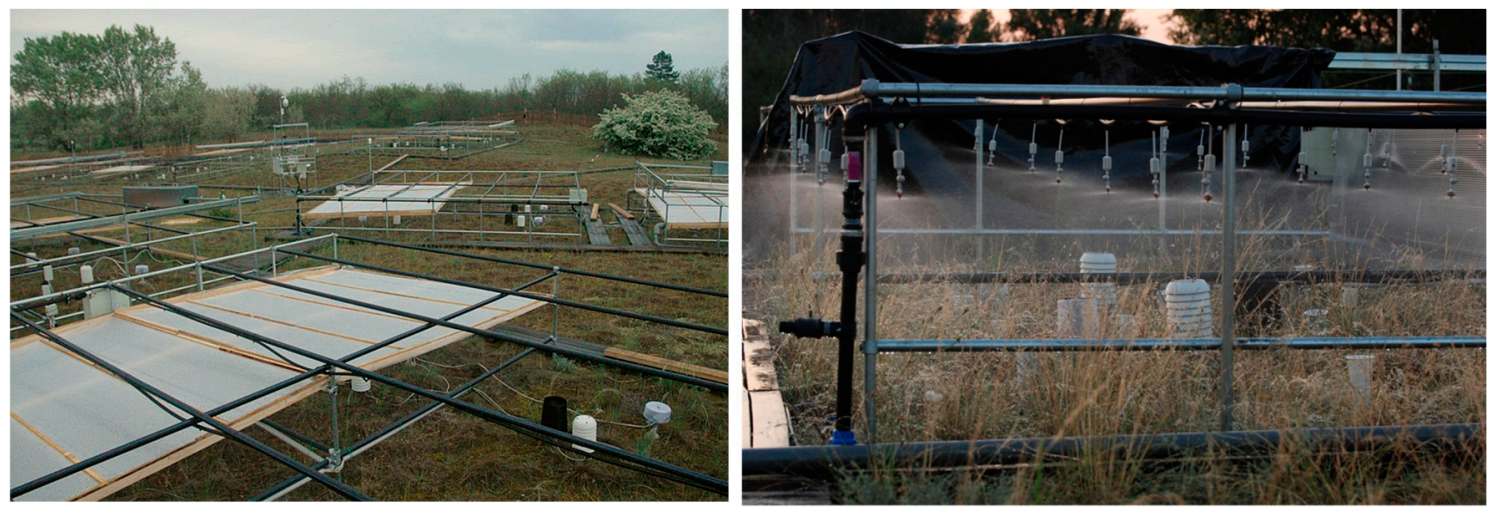

Figure 2. Left picture shows the removable plastic roofs used to exclude from rainfall for drought treatments in the ExDRain experiment and right picture the irrigating event for the watered plots.

\section{Materials and Methods}

\subsection{UAV and Equipment}

We used DJI Phantom 4+ quadcopter equipped with its original 4K 20 Mpix RGB CMOS camera plus a special mount designed to bring the camera Parrot Sequoia (Figure 3). This multispectral sensor captures images at 4 spectral bands (b1 green $-550 @ 40 \mathrm{~nm}, \mathrm{~b} 2$ red $-660 @ 40 \mathrm{~nm}, \mathrm{~b} 3$ red edge $-735 @ 10$ $\mathrm{nm}$ and b4 near infrared $-790 @ 40 \mathrm{~nm}$ ) with a vertical FOV of $48.5^{\circ}$, in addition to an RGB sensor which was shut off during this study. The Sequoia camera is connected to its own battery and provides wireless connection to be accessed and programmed through a computer. Additionally, the Sequoia camera brings a sensor of irradiance located in the upper part of the mount which is concurrently capturing irradiance while taking pictures [37]. A calibration panel is provided with every Sequoia camera to be pictured before flight allowing for bands' reflectance calculation after flight [38].

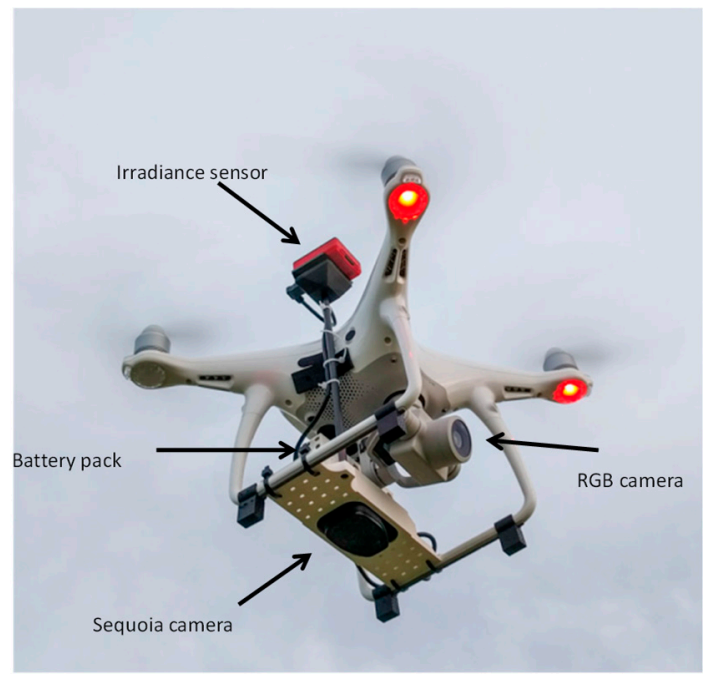

Figure 3. Unmanned Aerial Vehicle used for the study consisting of a DJI Phantom 4+ quadcopter equipped with its 4 K RGB camera and a specific mount for the Parrot Sequoia multispectral camera, including both the camera itself and the sunshine sensor (original design from Zcopters).

\subsection{Mission Planning and Geometric Processing}

On 30 July at solar noon and with clear sky conditions we flew the UAV Phantom 4 Pro + equipped with the Parrot Sequoia multispectral camera over the whole ExDRain area ( 0.31 ha from 3.86 ha total flight area, Figure 4). One single flight of 14 minutes was carried out at $50 \mathrm{~m}$ above ground seeking 
to produce output images of $5.50 \mathrm{~cm}$ of nominal ground sampling distance (GSD) for Sequoia bands and 1.43 for the RGB 4K camera. The flight was carried out at the lowest speed to increase platform stability $[39,40]$. Radiometric calibration was simply achieved by reflectance calculation according to radiance coefficients and irradiance measured at every picture centre [41]. Vignetting correction was applied in the process. Mission planning was carried out using Pix4DMapper@ software for Android devices which allows for the design of grid missions and defining all flight parameters. Pictures lateral and longitudinal overlap was defined as $80 \%$ both for DJI Phantom 4 Pro+ mission and for Sequoia camera which calculates the corresponding time and distance between camera shots.
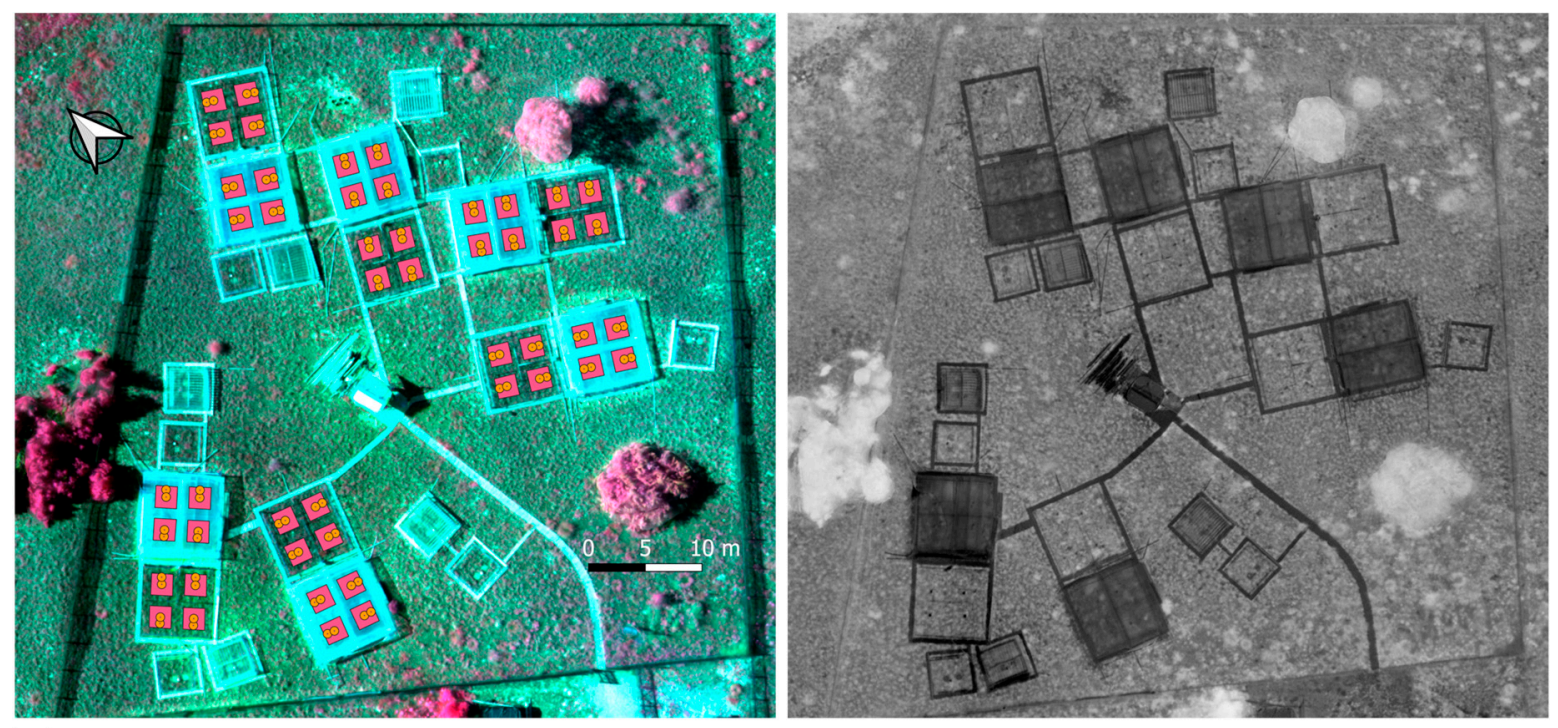

Plot $\bigcirc$ Cropscan footprint $\bullet$ Measurement location

Figure 4. Left image shows a false color RGB composite with near infrared-red edge-red Sequoia bands with the overlay of plot limits, Cropscan sampling footprints and measurement location points. Right image shows Normalized Difference Vegetation Index (NDVI) image calculated with Sequoia near infrared and red bands evidencing the plots covered by plastic (darker plots).

We located 16 ground control points (GCPs) with a differential GPS providing centimetric precision ( $20 \mathrm{~cm}$ on-site precision and $4 \mathrm{~cm}$ after post-processing) to improve geometric accuracy of the outputs to be produced. Images are automatically geotagged by Sequoia camera and the set of pictures were introduced into Pix4DMapper@ software (Pix4D S.A., Lausanne, Switzerland) to be stitched and generate a multispectral orthomosaic together with digital surface model [42]. Ground control points are plotted on top of a point cloud at the intermediate step in the processing to provide a 3D Root Mean Square (RMS) error for the output. The NDVI image from Sequoia was generated using near infraredand red bands (Figure 4). Additionally, we processed the images acquired by the $4 \mathrm{~K}$ RGB camera with a GSD of $1.43 \mathrm{~cm}$ to improve the geolocation of the periodical Cropscan point measurements.

\subsection{Ground-Truth Sampling and Assessment of Plastic Effect}

Cropscan periodical measurements were carried out during the previous week to the UAV flight when plastic roofs were removed. As data capture campaigns are too intensive and Cropscan measurements have to be also acquired close to noon, we could not fly with UAV and Sequoia camera on board exactly at the same time of acquisition. The experiment had to be strictly applied so that plastic roofs were mounted during UAV flight.

Therefore, as half of the plots were covered with plastic to exclude rain, we collected spectral signature of a calibration panel with Cropscan and Sequoia both above and below the plastic to assess 
plastic's effect on reflectance and irradiance. Image processing and data download was started once back at the office of the station.

Parallel ground measurements during UAV flight were also collected for several plots both with CropScan spectroradiometer and Sequoia camera in order to compare both sensors for the similar spectral wavelengths. These measurements were geolocated with sub-metric precision as well.

\subsection{Multiscale Analysis and Spatial Variability}

We compared NDVI Cropscan ground measurements for every plot with NDVI values from the Sequoia multispectral orthomosaic at 3 scales:

1. Pixel value at the point scale $(n=96)$.

2. Average value at the FOV scale $(0.75 \mathrm{~m}$ diameter buffer around point measurements, $n=96)$.

3. Average value at the plot scale $(3 \times 3 \mathrm{~m}, n=48)$.

The purpose of this analysis was to find the best related scale between both sensors and to assess sensor comparison. We used the lineal coefficient of determination $\mathrm{R}^{2}$ for every scale comparison.

Finally, we compared spatial NDVI variability using standard deviation, Moran and Shannon Indices at plot scales taking advantage from the additional spatial information provided by Sequoia multispectral orthomosaic. This analysis will enable us to assess plot spatial heterogeneity, autocorrelation and how the Cropscan NDVI FOV measurements are related to Sequoia NDVI for plots identified per treatment.

\section{Results}

\subsection{Geometric Accuracy of UAV Multispectral and RGB Orthomosaics}

Table 1 shows the geometric characteristics of the two produced orthomosaics. Absolute root mean square errors (RMSEs) of the multispectral orthomosaic was below 1 pixel. However, it was bigger than 1 pixel for the RGB orthomosaic. Figure 4 shows a Sequoia false colour composite (NIR-RedEdge-Red) of the ExDRain experimental area and the NDVI image.

Table 1. Geometric characteristics of the UAV missions carried out over Doñana and Braila.

\begin{tabular}{ccc}
\hline Flight Characteristics & Multispectral & RGB 4K Camera \\
\hline Ground Sampling Distance $(\mathrm{cm})$ & 5.5 & 1.45 \\
Number of images & 1064 & 135 \\
Absolute RMS error $(\mathrm{cm})$ & 4.8 & 2.5 \\
\hline
\end{tabular}

Location of Cropscan point measurements were revised and re-located using reference elements which were very conspicuous in both orthomosaics.

\subsection{Plastic Effect}

Spectral reflectance and irradiance captured above and below plastic roofs show overall lower values while measured under plastic (Figure 5). The effect on the irradiance is higher than for reflectance being magnified for short wavelengths.

The NDVI calculated from these measurements are higher for plastic covered plots when Cropscan was used below the plastic $\left(\mathrm{R}^{2}=0.81, p<0.01, n=8\right)$. Nevertheless, the relationship was lineal and underestimation was proportional to the measured values under plastic. 

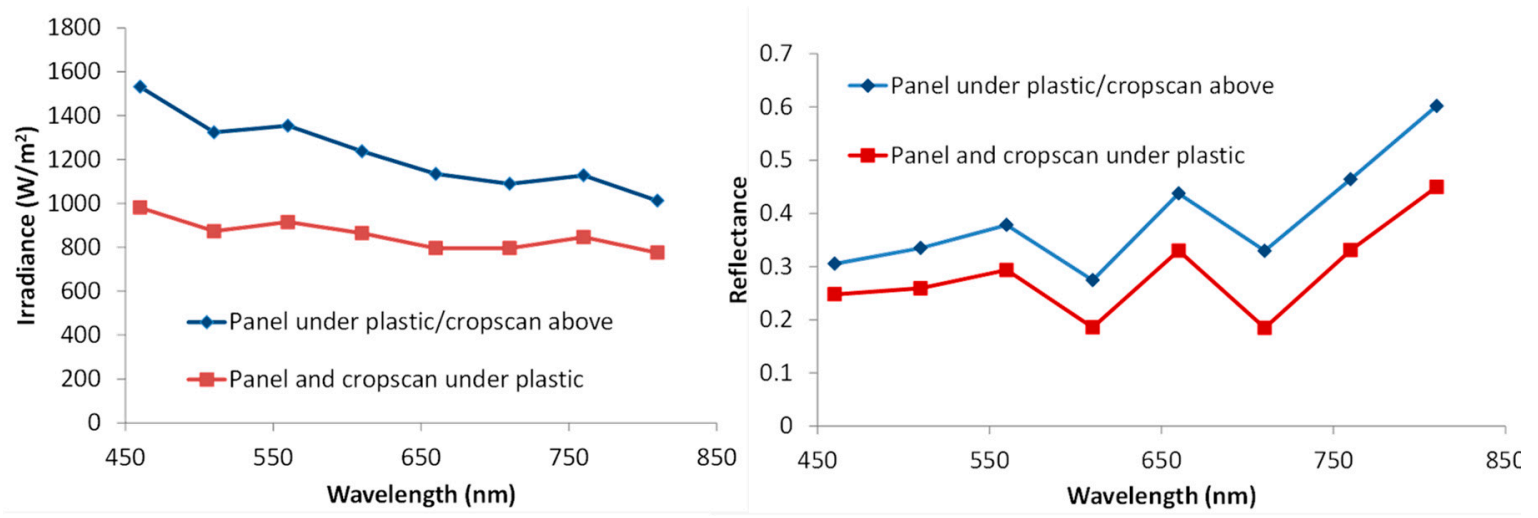

Figure 5. Left chart shows irradiance values collected with Cropscan spectroradiometer above and below plastic covered plots on a grey calibration panel. Right chart displays the corresponding reflectance values.

\subsection{Multiscale Comparison}

Table 2 shows the coefficient of determination $\left(R^{2}\right)$ between the Cropscan and Sequoia NDVI values at different scales. Results are shown for all plots together and separately for plastic covered plots and uncovered ones. An acceptable positive and significant relationship was maintained between both sensors at the different scales, being lower at plot scale and higher at FOV scale for all measurements, covered and uncovered plots. Plastic covered plots systematically showed lower Sequoia NDVI values although proportional to those measured below plastic cover.

Table 2. $\mathrm{R}^{2}$ values between Cropscan and Sequoia NDVI values for the different measurement scales ( $n=96$ for point and FOV measurements, $n=48$ for plots). $\mathrm{R}^{2}$ values between data from plastic covered and uncovered plots are also provided (sample size is divided by two). All $R^{2}$ values were significant at $p<0.01$.

\begin{tabular}{cccc}
\hline Scales & All Measurements & Plastic Cover & No Plastic \\
\hline Point scale & 0.43 & 0.31 & 0.37 \\
FOV scale (circle, 40 cm radius) & 0.46 & 0.41 & 0.65 \\
Plot scale & 0.38 & 0.21 & 0.33 \\
\hline
\end{tabular}

Figure 6 shows the overall relationship between NDVI values of Cropscan and Sequoia at plot scale $\left(\mathrm{R}^{2}=0.38, p<0.01, n=48\right)$ with different markers as a function of the treatment.

We assessed treatments effect on Sequoia and Cropscan NDVI values. Aggregated Cropscan values (two FOV measurements per plot) were much more similar among treatments than Sequoia NDVI values at plot scale (Figure 7). Values for the covered plots were lower which can be due to the plastic effect but they still follow the measured trend by Cropscan, i.e., plots submitted to moderate drought show higher values than those under severe drought treatment. Yet, drought treatments significantly showed lower NDVI values than control and watered treatments (one sample $t$-test $\mathrm{t}=2.79, p<0.01, n=24$ ). Plots submitted to extreme drought effect did not show significant differences within treatment neither with Sequoia average NDVI values per plot nor with Cropscan point measurements (Figure 7). 


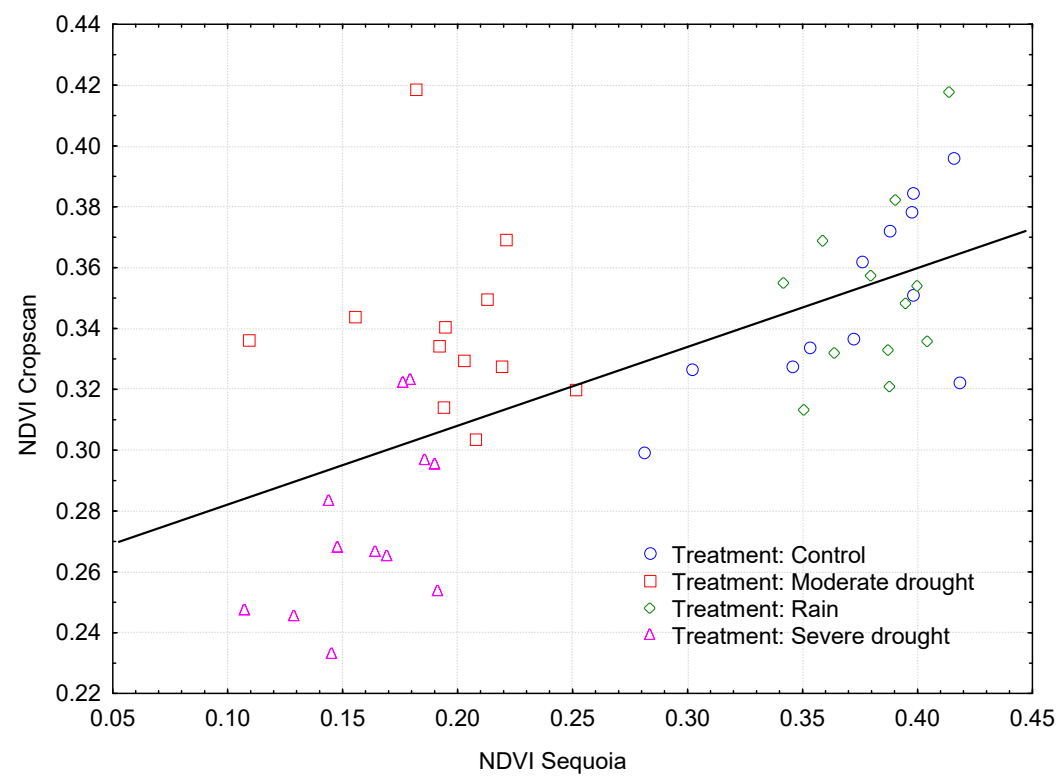

Figure 6. Scatterplot of Cropscan and Sequoia NDVI values for all plots. Different markers are used to distinguish among treatments. Linear fit is also shown $\left(\mathrm{R}^{2}=0.38, p<0.01, n=48\right)$.
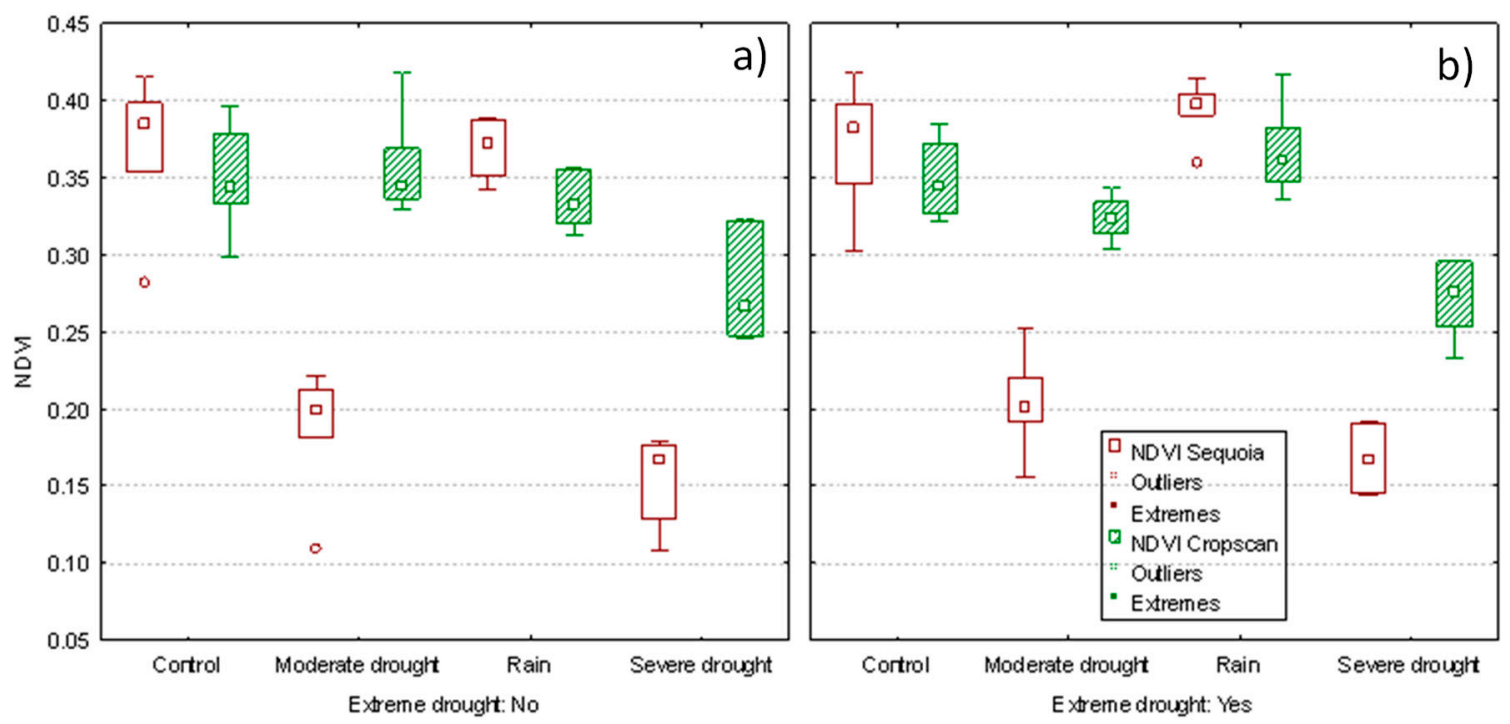

Figure 7. Boxplots of NDVI values from Cropscan and Sequoia plot measurements according to experimental treatments: control/moderate/severe drought/rainfed. Boxplot (a) shows the values for those plots that were not submitted to extreme drought in 2014 and boxplot (b) shows the values for those plots submitted to extreme drought.

We also assessed spatial variability within plots since Sequoia data provides much more information for every single plot than Cropscan. Figure 8 depicts the standard deviation for Sequoia NDVI values per plot indicating more spatial variability within control and watered plots than for plots submitted to moderate and severe drought. 

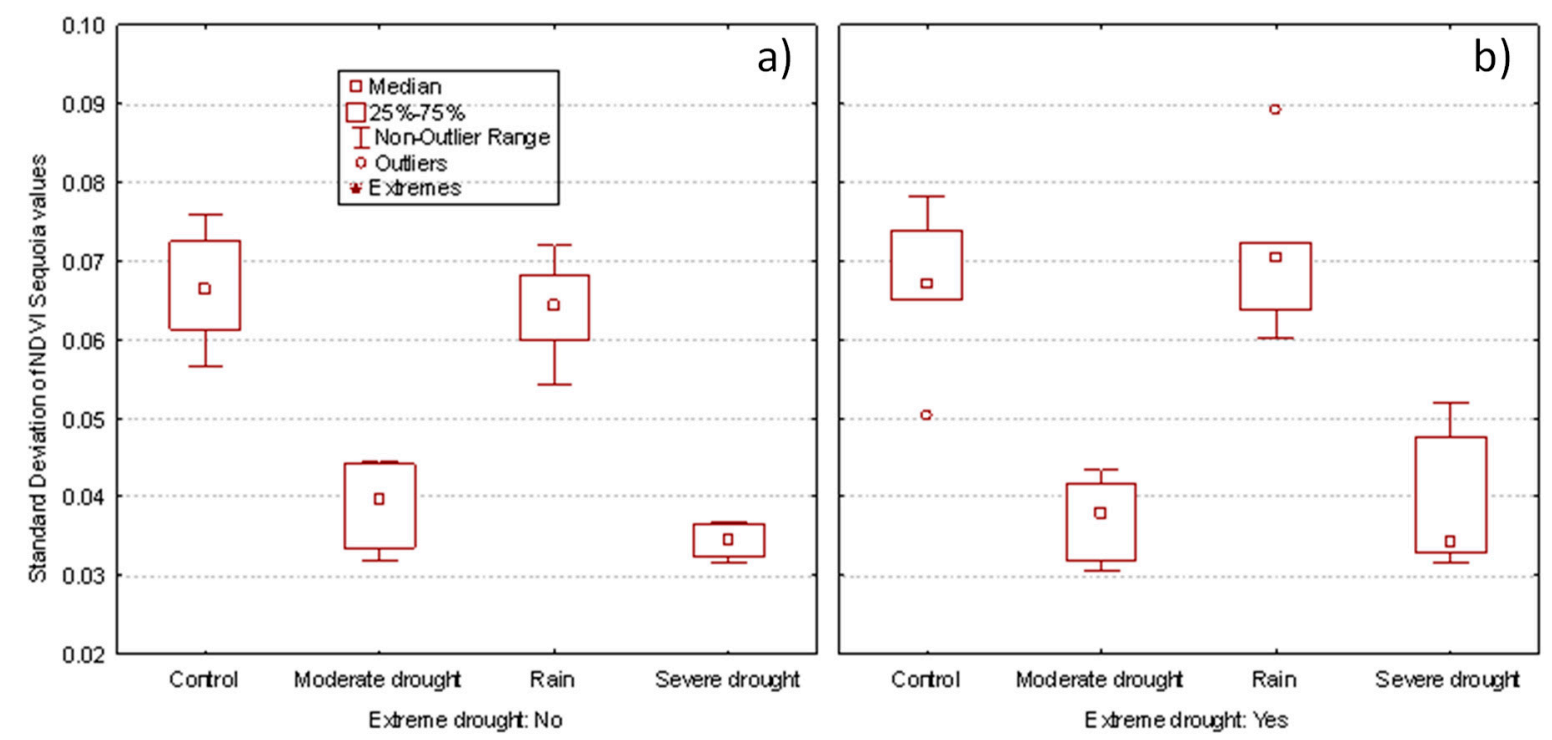

Figure 8. Boxplot of standard deviation for Sequoia NDVI values of ExDRain plots according to treatments. Boxplot (a) shows the values for those plots that were not submitted to extreme drought in 2014 and boxplot (b) shows the values for those plots submitted to extreme drought.

Average Moran Index values per treatment calculated from Sequoia NDVI values per plot revealed lower spatial autocorrelation for control and watered treatments than for both drought treatments (Table 3). Spatial autocorrelation of control and watered plots is lower, and therefore plots appear more heterogeneous in terms of NDVI variability. Conversely, either moderate or severe drought treatments manifest a higher homogeneity in NDVI values which might indicate a more homogeneous response to treatments. Yet, extreme drought event only is evidenced for severe drought treatment where the plots with the two treatments show higher spatial autocorrelation or a more homogeneous response. Shannon index did show a very low variability with a very similar pattern.

Table 3. Average Moran and Shannon Indices per treatment from NDVI Sequoia values at plot scale.

\begin{tabular}{cccc}
\hline Treatment & Extreme Drought & Moran Index & Shannon Index \\
\hline \multirow{2}{*}{ Control } & No & 0.8522 & 10.3499 \\
& Yes & 0.8473 & 10.3530 \\
\hline \multirow{2}{*}{ Moderate drought } & No & 0.9077 & 10.3525 \\
& Yes & 0.9043 & 10.3478 \\
\hline \multirow{2}{*}{ Rain } & No & 0.8440 & 10.3417 \\
& Yes & 0.8729 & 10.3522 \\
\hline \multirow{2}{*}{ Severe drought } & No & 0.8834 & 10.3462 \\
& Yes & 0.9195 & 10.3567 \\
\hline
\end{tabular}

\section{Discussion}

Our study provides a first basis for the implementation of multiscale methodological approaches on field experimental sites. Rapid and easy deployment and flight of UAVs equipped with multispectral cameras can enhance and complement the results from these experiments by providing data from surrounding pixels not measured in the experiment. In our case, the use of Sequoia multispectral camera contributed to confirm the measured trends using Cropscan spectroradiometer at ground scale. The NDVI values retrieved from Sequoia measurements were significantly related to Cropscan measurements at different scales (Table 2), being weaker at plot scale and higher at FOV scale for uncovered plots and for all measurements. A lower relationship at plot scale may be revealing not necessarily an increase in sensor discrepancies but an influence of surrounding pixels in the treatment 
effect for the full plot. Such findings reveal a scale effect on treatments which has to be considered. The use of drone multispectral images clearly enhances the information of treatments effects on vegetation. So far, most of the multiscale approaches using UAVs have been applied in agricultural studies [18], showing that vegetation indices derived from the use of UAVs are reliable for assessing effects of experimental plots [43]. As UAVs are becoming widely available, its systematic use will certainly complement the data collected at ground scale. Much work has been done over crops evidencing the plausibility of upscaling essential information on crop health [15-17]. However, it is crucial to understand the critical difference between crops and natural grasslands, as essentially being manifested in the spatial distribution of individuals (homogeneous fields with similar growth and health versus heterogeneous growth, phenology and foliar greenness) and different species composition. Our main intention in this study was to show the spatial differences as a response to experimental treatments as an enhancement of such information by using UAVs.

One big constraint of the study was the presence of plastic roofs over the treated plots. Plastic effect on measurements consequently showed lower NDVI Sequoia values and higher Cropscan values measured under the plastic cover (due to reduced irradiance). Transparent plastic-mulch film allows visible lights to penetrate, but blocks outgoing long-wave radiation, and thus causes the greenhouse effect [44]. Levin et al. [45] claimed that white and transparent plastic-mulch films have three absorptions centred at 1218, 1732 and $2313 \mathrm{~nm}$ that are not affected by dust, rinse and surface factors. In our case, we did not use any of these wavelengths and plastic effect can be considered as negligible while making comparisons only among plastic covered plots.

Sequoia NDVI average values revealed much bigger differences between treatments than Cropscan FOV measurements (Figure 5), but this effect cannot be separated from the plastic effect as shown for Sequoia NDVI lower values. Significant differences are found between drought treatments (severe and moderate) and control/watered treatments for Sequoia. Extreme drought effect was evident neither with Cropscan nor with Sequoia measurements. These results are compliance with major findings from the VULCAN/INCREASE experiment which revealed that recurring drought treatment (precipitation exclusion) leads to mid-season reduction of aboveground biomass [6]. This is coherent with the results obtained by using NDVI from multispectral Sequoia on board of UAV.

Species composition has also been assessed under ExDRain experiment and it changed considerably in response to both extreme drought and long-term precipitation changes (unpublished data). Although UAV mapping could not deal with species mapping in this case, plant species variability might have an effect on NDVI values and therefore on spatial NDVI variability [46]. Actually, we were able to detect spatial variability within plots manifested for the treatments as more homogeneous response in plots under drought treatment according to SD and Moran Autocorrelation Index (Figure 8 and Table 3). Such finding may indicate heterogeneous responses to treatments based on the NDVI values at plot scale which are not considered at Cropscan FOV scale of measurement. Spatial variability might be due to different abundance on plant species and their spatial distribution patterns within plots, but this has to be investigated. Sha et al. [19] found better estimates of Leaf Area Index (LAI) values over sparsely vegetated areas as in our case. On the other hand, it also points out the need to assess the homogeneity of the measured effect per plot and per treatment in order to increase the consistency of the results. An analogous effect has been found for the temporal scale in the VULCAN/INCREASE experiment where results show that the effect of drought treatment can be overestimated with only one measurement at the time of the peak biomass, while multiple within-year measurements better describe the response of biomass [27].

One major challenge for these studies, where point measurements have to be located in high resolution orthomosaics, is the need to precisely geo-locate such measurements to guarantee a reliable data comparison. Even though high precision DGPS were used providing centimetric precision, RMS errors from the orthomosaics are close or are even bigger than final GSD. Therefore, the combined use of multispectral with RGB high-resolution images can clearly assist in re-locating the point measurements by identifying conspicuous elements in the image. 


\section{Conclusions}

In this paper we confirmed the valuable and fast applicability of multispectral images captured by UAVs over experimental sites in providing complementary spatial information to the ground measurements at point scale. One single flight was used to confirm acceptable multiscale NDVI correlations being measured at point, FOV or plot scale. Although plastic covered plots reduced the NDVI values, main differences between treatments were coherent with the ones measured at ground scale with portable Cropscan spectroradiometer. Differences found at plot scale might be due to heterogeneous response to treatments. Spatial variability analysis pointed out a more homogeneous response for plots submitted to severe and moderate drought. More investigation is needed to address the possible effect on NDVI of species abundance at plot scale contributing to a more consistent representation of ground measurements. The feasibility to carry out systematic UAV flights in the future coincident or close to ground campaigns will certainly reveal the consistency of the observed spatial patterns in the long run.

Author Contributions: Conceptualization, R.D.-D. and M.K.; Data curation, R.D.-D., G.Ó. and M.K.; Formal analysis, R.D.-D.; Funding acquisition, R.D.-D. and M.K.; Investigation, R.D.-D., Gy.K.-D. and M.K.; Methodology, R.D.-D., G.Ó. and M.K.; Project administration, Gy.K.-D. and M.K.; Resources, G.Ó. and M.K.; Supervision, M.K.; Validation, R.D.-D., G.Ó. and M.K.; Visualization, G.Ó.; Writing—original draft, R.D.-D.; Writing—review \& editing, R.D.-D..

Funding: This research was funded by the European Union's Horizon 2020 Research and Innovation Program under grant agreement No. 654359 (eLTER Horizon 2020 project). Gy. K-D. was supported by the National Research, Development and Innovation Fund (NRDI Fund) of Hungary (Nos. K112576, K129068).

Acknowledgments: The authors want to thank the funding by the European Union's Horizon 2020 Research and Innovation Program under grant agreement No. 654359 (eLTER Horizon 2020 project). Gy. K-D. was supported by the National Research, Development and Innovation Fund (NRDI Fund) of Hungary (Nos. K112576, K129068). We are grateful to the Hungarian Academy of Sciences which provided permits for fieldwork in the Kiskun ExDRain experiment.

Conflicts of Interest: The authors declare no conflict of interest. The founding sponsors had no role in the design of the study; in the collection, analyses, or interpretation of data; in the writing of the manuscript, and in the decision to publish the results.

\section{References}

1. Haase, P.; Tonkin, J.D.; Stoll, S.; Burkhard, B.; Frenzel, M.; Geijzendorffer, I.R.; Häuser, C.; Klotz, S.; Kühn, I.; McDowell, W.H.; et al. The next generation of site-based long-term ecological monitoring: Linking essential biodiversity variables and ecosystem integrity. Sci. Total Environ. 2018, 613-614, 1376-1384. [CrossRef] [PubMed]

2. Schimel, D.; Hargrove, W.; Hoffman, F.; MacMahon, J. NEON: A hierarchically designed national ecological network. Front. Ecol. Environ. 2007, 5, 59. [CrossRef]

3. Peterson, T.; Daan, H.; Jones, P. Initial Selection of a GCOS Surface Network. Bull. Am. Meteorol. Soc. 1997, 78, 2145-2152. [CrossRef]

4. Clobert, J.; Chanzy, A.; Le Galliard, J.-F.; Chabbi, A.; Greiveldinger, L.; Caquet, T.; Loreau, M.; Mougin, C.; Pichot, C.; Roy, J.; et al. How to Integrate Experimental Research Approaches in Ecological and Environmental Studies: AnaEE France as an Example. Front. Ecol. Evol. 2018, 6. [CrossRef]

5. Knapp, A.K.; Avolio, M.L.; Beier, C.; Carroll, C.J.W.; Collins, S.L.; Dukes, J.S.; Fraser, L.H.; Griffin-Nolan, R.J.; Hoover, D.L.; Jentsch, A.; et al. Pushing precipitation to the extremes in distributed experiments: recommendations for simulating wet and dry years. Glob. Change Biol. 2017, 23, 1774-1782. [CrossRef] [PubMed]

6. Ónodi, G.; Botta-Dukát, Z.; Kröel-Dulay, G.; Lellei-Kovács, E.; Kertész, M. Reduction in primary production followed by rapid recovery of plant biomass in response to repeated mid-season droughts in a semiarid shrubland. Plant Ecol. 2018, 219, 517-526. [CrossRef]

7. Peterson, D.L.; Waring, R.H. Overview of the Oregon Transect Ecosystem Research Project. Ecol. Appl. 1994, 4, 211-225. [CrossRef] 
8. Li, X.; Liu, S.; Xiao, Q.; Ma, M.; Jin, R.; Che, T.; Wang, W.; Hu, X.; Xu, Z.; Wen, J.; et al. A multiscale dataset for understanding complex eco-hydrological processes in a heterogeneous oasis system. Sci. Data 2017, 4, 170083. [CrossRef] [PubMed]

9. Gardner, R.H.; Kemp, W.M.; Kennedy, V.S.; Petersen, J.E. Scaling Relations in Experimental Ecology; Columbia University Press: New York, NY, USA, 2012; ISBN 978-0-231-52904-4.

10. Díaz-Delgado, R.; Hurford, C.; Lucas, R. Introducing the Book “The Roles of Remote Sensing in Nature Conservation.". In The Roles of Remote Sensing in Nature Conservation; Springer: Cham, Switzerland, 2017; pp. 3-10, ISBN 978-3-319-64330-4.

11. Hufkens, K.; Bogaert, J.; Dong, Q.H.; Lu, L.; Huang, C.L.; Ma, M.G.; Che, T.; Li, X.; Veroustraete, F.; Ceulemans, R. Impacts and uncertainties of upscaling of remote-sensing data validation for a semi-arid woodland. J. Arid Environ. 2008, 72, 1490-1505. [CrossRef]

12. Porcar-Castell, A.; Mac Arthur, A.; Rossini, M.; Eklundh, L.; Pacheco-Labrador, J.; Anderson, K.; Balzarolo, M.; Martín, M.P.; Jin, H.; Tomelleri, E.; et al. EUROSPEC: at the interface between remote-sensing and ecosystem $\mathrm{CO}_{2}$ flux measurements in Europe. Biogeosciences 2015, 12, 6103-6124. [CrossRef]

13. Zarco-Tejada, P.J.; Miller, J.R.; Noland, T.L.; Mohammed, G.H.; Sampson, P.H. Scaling-up and model inversion methods with narrowband optical indices for chlorophyll content estimation in closed forest canopies with hyperspectral data. IEEE Trans. Geosci. Remote Sens. 2001, 39, 1491-1507. [CrossRef]

14. Lucas, R.; Díaz-Delgado, R.; Hurford, C. Expected Advances in a Rapidly Developing Work Area. In The Roles of Remote Sensing in Nature Conservation; Springer: Cham, Switzerland, 2017; pp. 309-318, ISBN 978-3-319-64330-4.

15. Duan, T.; Chapman, S.C.; Guo, Y.; Zheng, B. Dynamic monitoring of NDVI in wheat agronomy and breeding trials using an unmanned aerial vehicle. Field Crops Res. 2017, 210, 71-80. [CrossRef]

16. Su, J.; Liu, C.; Coombes, M.; Hu, X.; Wang, C.; Xu, X.; Li, Q.; Guo, L.; Chen, W.-H. Wheat yellow rust monitoring by learning from multispectral UAV aerial imagery. Comput. Electron. Agric. 2018, 155, 157-166. [CrossRef]

17. Zhang, C.; Kovacs, J.M. The application of small unmanned aerial systems for precision agriculture: a review. Precis. Agric. 2012, 13, 693-712. [CrossRef]

18. Manfreda, S.; McCabe, M.; Miller, P.; Lucas, R.; Pajuelo Madrigal, V.; Mallinis, G.; Ben Dor, E.; Helman, D.; Estes, L.; Ciraolo, G.; et al. On the Use of Unmanned Aerial Systems for Environmental Monitoring. Remote Sens. 2018, 10, 641. [CrossRef]

19. Sha, Z.; Wang, Y.; Bai, Y.; Zhao, Y.; Jin, H.; Na, Y.; Meng, X. Comparison of leaf area index inversion for grassland vegetation through remotely sensed spectra by unmanned aerial vehicle and field-based spectroradiometer. J. Plant Ecol. 2018. [CrossRef]

20. Vanden Borre, J.; Paelinckx, D.; Mücher, C.A.; Kooistra, L.; Haest, B.; De Blust, G.; Schmidt, A.M. Integrating remote sensing in Natura 2000 habitat monitoring: Prospects on the way forward. J. Nat. Conserv. 2011, 19, 116-125. [CrossRef]

21. Lloret, F.; de la Riva, E.G.; Pérez-Ramos, I.M.; Marañón, T.; Saura-Mas, S.; Díaz-Delgado, R.; Villar, R. Climatic events inducing die-off in Mediterranean shrublands: are species' responses related to their functional traits? Oecologia 2016, 180, 1-13. [CrossRef] [PubMed]

22. Ciais, P.; Reichstein, M.; Viovy, N.; Granier, A.; Ogée, J.; Allard, V.; Aubinet, M.; Buchmann, N.; Bernhofer, C.; Carrara, A.; et al. Europe-wide reduction in primary productivity caused by the heat and drought in 2003. Nature 2005, 437, 529-533. [CrossRef]

23. de la Riva, E.G.; Lloret, F.; Pérez-Ramos, I.M.; Marañón, T.; Saura-Mas, S.; Díaz-Delgado, R.; Villar, R. The importance of functional diversity on the stability of Mediterranean shrubland communities after the impact of extreme climatic events. J. Plant Ecol. 2017, 10, 281-293. [CrossRef]

24. Kröel-Dulay, G.; Ransijn, J.; Schmidt, I.K.; Beier, C.; De Angelis, P.; de Dato, G.; Dukes, J.S.; Emmett, B.; Estiarte, M.; Garadnai, J.; et al. Increased sensitivity to climate change in disturbed ecosystems. Nat. Commun. 2015, 6, 6682. [CrossRef] [PubMed]

25. Lellei-Kovács, E.; Kovács-Láng, E.; Kalapos, T.; Botta-Dukát, Z.; Barabás, S.; Beier, C. Experimental warming does not enhance soil respiration in a semiarid temperate forest-steppe ecosystem. Community Ecol. 2008, 9, 29-37. [CrossRef]

26. Rouse, J.W. Monitoring the Vernal Advancement and Retrogradation (Green Wave Effect) of Natural Vegetation; Texas A\&M Univ.; Remote Sensing Center: College Station, TX, USA, 1974. 
27. Ónodi, G.; Kröel-Dulay, G.; Kovács-Láng, E.; Ódor, P.; Botta-Dukat, Z.; Lhotsky, B.; Barabás, S.; Garadnai, J.; Kertész, M. Comparing the accuracy of three non-destructive methods in estimating aboveground plant biomass. Community Ecol. 2017, 18, 56-62. [CrossRef]

28. Molnár, Z.; Biró, M.; Bartha, S.; Fekete, G. Past Trends, Present State and Future Prospects of Hungarian Forest-Steppes. In Eurasian Steppes. Ecological Problems and Livelihoods in a Changing World; Werger, M.J.A., van Staalduinen, M.A., Eds.; Plant and Vegetation; Springer Netherlands: Dordrecht, The Netherlands, 2012; pp. 209-252, ISBN 978-94-007-3886-7.

29. Kovács-Láng, E.; Kröel-Dulay, G.; Kertész, M.; Fekete, G.; Bartha, S.; Mika, J.; Dobi-Wantuch, I.; Rédei, T.; Rajkai, K.; Hahn, I. Changes in the composition of sand grasslands along a climatic gradient in Hungary and implications for climate change. Phytocoenologia 2000, 30, 385-407. [CrossRef]

30. Bartholy, J.; Pongrácz, R. Regional analysis of extreme temperature and precipitation indices for the Carpathian Basin from 1946 to 2001. Glob. Planet. Change 2007, 57, 83-95. [CrossRef]

31. Beier, C.; Emmett, B.; Gundersen, P.; Tietema, A.; Peñuelas, J.; Estiarte, M.; Gordon, C.; Gorissen, A.; Llorens, L.; Roda, F.; et al. Novel Approaches to Study Climate Change Effects on Terrestrial Ecosystems in the Field: Drought and Passive Nighttime Warming. Ecosystems 2004, 7, 583-597. [CrossRef]

32. Peñuelas, J.; Prieto, P.; Beier, C.; Cesaraccio, C.; Angelis, P.D.; Dato, G.D.; Emmett, B.A.; Estiarte, M.; Garadnai, J.; Gorissen, A.; et al. Response of plant species richness and primary productivity in shrublands along a north-south gradient in Europe to seven years of experimental warming and drought: reductions in primary productivity in the heat and drought year of 2003. Glob. Change Biol. 2007, 13, 2563-2581. [CrossRef]

33. Díaz-Delgado, R.; Lloret, F.; Pons, X.; Terradas, J. Satellite Evidence of Decreasing Resilience in Mediterranean Plant Communities After Recurrent Wildfires. Ecology 2002, 83, 2293-2303. [CrossRef]

34. Haberl, H.; Winiwarter, V.; Andersson, K.; Ayres, R.U.; Boone, C.; Castillo, A.; Cunfer, G.; Fischer-Kowalski, M.; Freudenburg, W.R.; Furman, E.; et al. From LTER to LTSER: Conceptualizing the socioeconomic dimension of long-term socioecological research. Ecol. Soc. 2006, 11, 13. [CrossRef]

35. Mirtl, M.; Orenstein, D.E.; Wildenberg, M.; Peterseil, J.; Frenzel, M. Development of LTSER Platforms in LTER-Europe: Challenges and Experiences in Implementing Place-Based Long-Term Socio-ecological Research in Selected Regions; Springer Netherlands: Dordrecht, The Netherlands, 2013; ISBN 978-94-007-1176-1.

36. Dick, J.; Orenstein, D.E.; Holzer, J.; Wohner, C.; Achard, A.-L.; Andrews, C.; Avriel-Avni, N.; Beja, P.; Blond, N.; Cabello, J.; et al. What is socio-ecological research delivering? A literature survey across 25 international LTSER platforms. Sci. Total Environ. 2018, 622-623, 1225-1240. [CrossRef]

37. Franklin, S.E.; Ahmed, O.S.; Williams, G. Northern Conifer Forest Species Classification Using Multispectral Data Acquired from an Unmanned Aerial Vehicle. Photogramm. Eng. Remote Sens. 2017, 83, 501-507. [CrossRef]

38. Shen, Y.-Y.; Cattau, M.; Borenstein, S.; Weibel, D.; Frew, E.W. Toward an Architecture for Subalpine Forest Health Monitoring Using Commercial Off-the-Shelf Unmanned Aircraft Systems and Sensors. Proceedings of 17th AIAA Aviation Technology, Integration, and Operations Conference, Denver, CO, USA, 5-9 June 2017.

39. Padró, J.-C.; Carabassa, V.; Balagué, J.; Brotons, L.; Alcañiz, J.M.; Pons, X. Monitoring opencast mine restorations using Unmanned Aerial System (UAS) imagery. Sci. Total Environ. 2019, 657, 1602-1614. [CrossRef]

40. Hakala, T.; Markelin, L.; Honkavaara, E.; Scott, B.; Theocharous, T.; Nevalainen, O.; Näsi, R.; Suomalainen, J.; Viljanen, N.; Greenwell, C.; et al. Direct Reflectance Measurements from Drones: Sensor Absolute Radiometric Calibration and System Tests for Forest Reflectance Characterization. Sensors 2018, 18, 1417. [CrossRef] [PubMed]

41. Ahmed, O.S.; Shemrock, A.; Chabot, D.; Dillon, C.; Williams, G.; Wasson, R.; Franklin, S.E. Hierarchical land cover and vegetation classification using multispectral data acquired from an unmanned aerial vehicle. Int. J. Remote Sens. 2017, 38, 2037-2052. [CrossRef]

42. Unger, J.; Reich, M.; Heipke, C. UAV-based photogrammetry: monitoring of a building zone. Int. Arch. Photogramm. Remote Sens. Spat. Inf. Sci. 2014, XL, 601-606. [CrossRef]

43. Rasmussen, J.; Ntakos, G.; Nielsen, J.; Svensgaard, J.; Poulsen, R.N.; Christensen, S. Are vegetation indices derived from consumer-grade cameras mounted on UAVs sufficiently reliable for assessing experimental plots? Eur. J. Agron. 2016, 74, 75-92. [CrossRef]

44. Lu, B.; He, Y.; Liu, H.H.T. Mapping vegetation biophysical and biochemical properties using unmanned aerial vehicles-acquired imagery. Int. J. Remote Sens. 2017, 39, 1-23. [CrossRef] 
45. Levin, N.; Lugassi, R.; Ramon, U.; Braun, O.; Ben-Dor, E. Remote sensing as a tool for monitoring plasticulture in agricultural landscapes. Int. J. Remote Sens. 2007, 28, 183-202. [CrossRef]

46. Jiménez, M.; Díaz-Delgado, R. Sub-pixel Mapping of Doñana Shrubland Species. In The Roles of Remote Sensing in Nature Conservation; Springer: Cham, Switzerland, 2017; pp. 141-163, ISBN 978-3-319-64330-4.

(c) 2019 by the authors. Licensee MDPI, Basel, Switzerland. This article is an open access article distributed under the terms and conditions of the Creative Commons Attribution (CC BY) license (http://creativecommons.org/licenses/by/4.0/). 